\title{
Central responses to electrical activation of the peripheral nerves supplying the intrinsic hand muscles
}

\author{
JACK THORNE \\ From the Neurology Research Unit, Churchill Hospital, Oxford, and Lincoln College, Oxford
}

The monosynaptic reflex which can be elicited from the large muscles of posture (Hoffman, 1918; Magladery, Porter, Park, and Teasdall, 1951a; Magladery, Teasdall, Park, and Porter, 1951b) in response to electrical activation of the mixed peripheral nerve has been used as an index of the central excitatory state in the study of human spinal cord physiology (Paillard, 1955, 1959; Hagbarth, 1962). An attempt to elicit similar low threshold responses from the small muscles of the hand of normal adult subjects was unsuccessful. Here instead a different response was obtained, occurring at a stimulus intensity above that for the alpha motor fibre threshold but at a latency similar to that expected from an $\mathrm{H}$ response. This was termed by Magladery the ' $F$ ' wave (Magladery et al., 1951a). Conduction velocity studies and the selective depression of the response by ischaemia led these authors to postulate that it represented a reflex arising from polysynaptic pathways probably mediated by group II spindle afferents. In 1956, Dawson and Merton proposed the view that the $F$ response consisted of 'recurrent' discharges from motor neurones activated antidromically. Hagbarth in 1962 was unable to decide the mode of origin of the $\mathrm{F}$ wave, as was Vyklický (1962). These authors considered that monosynaptic activation of motor neurones was a likely explanation for its production. Liberson, Zalis, Gratzer, and Grabinski (1963) treated the F wave as a true reflex in their study on the conduction velocity of afferent and efferent pathways in the ulnar nerve. Lastly, working with the small muscles of the foot of the cat, Wiesendanger and Gassell (1963) postulated that the response was, in fact, compounded of both a reflex and an antidromic component.

In this study, a summary is presented of the main differences between the late responses obtained from the intrinsic hand muscles and the monosynaptic reflex obtained from the gastrocnemius-soleus muscles and other large muscles of posture.

An examination of the identity of the motor units contained in the $F$ response compared with the response has been carried out using a bipolar concentric needle electrode. It will be shown that in the normal state, the $F$ response consists only of motor neurones contained in the direct motor $\frac{\bar{w}}{\vec{\phi}}$ response. In subjects with loss of integrity of the $\stackrel{\varnothing}{\AA}$ upper motor neurone, a true reflex component $\stackrel{\omega}{\%}$ emerges which is superimposed on the antidromic $\vec{\circ}$ response.

COMPARISON BETWEEN THE MONOSYNAPTIC REFLEX AND THE F RESPONSE

1 MUSCLES FROM WHICH RESPECTIVE SPINAL RE- $\infty$ SPONSES CAN BE ELICITED The monosynaptic reflex or $H$ reflex (Magladery et al., 1951a) has been found if o normal subjects in the large muscles of the lower limb 을 the soleus gastrocnemius group (Hoffmann, 1918 the quadriceps, and hamstrings (Magladery et alo 1951a). In the upper limb a low threshold, stable, reflex response has been obtained from the forearro $\frac{D}{3}$ flexors with stimulation of the median nerve in the cubital fossa. In pathological states of the upped. motor neurone, the muscles from which monosynap- $\overrightarrow{0}$ tic responses can be obtained increase in distribution, of being found in muscles where normally only $\mathbf{F}$ waves are obtained.

The late response to peripheral nerve stimulation found in the small muscles of the hand, termed the F wave by Magladery et al. (1951a), is found in the small muscles of the foot on stimulation of the lateral popliteal and anterior tibial nerves. It has also been observed in the calf muscles in tabes dorsalis and peripheral neuritis in the absence of tendon reflexes and monosynaptic reflexes (Magladery and McDougall, 1950). In the course of the present study, responses resembling the $F$ response in all its major characteristics have been found in the calf muscles of $\frac{\sigma}{3}$ patients with tabes dorsalis (two subjects), the Holmes Adie syndrome (two subjects), with absent reflexes in the muscles being examined, and in two patients diagnosed as suffering from congenital 윽 sensory neuropathy who again lacked tendon reflexes $D$ and in addition had severely depressed peripheral 을. sensation and proprioception.

It was the finding of these responses in patients who, despite the clinical evidence of disturbed 

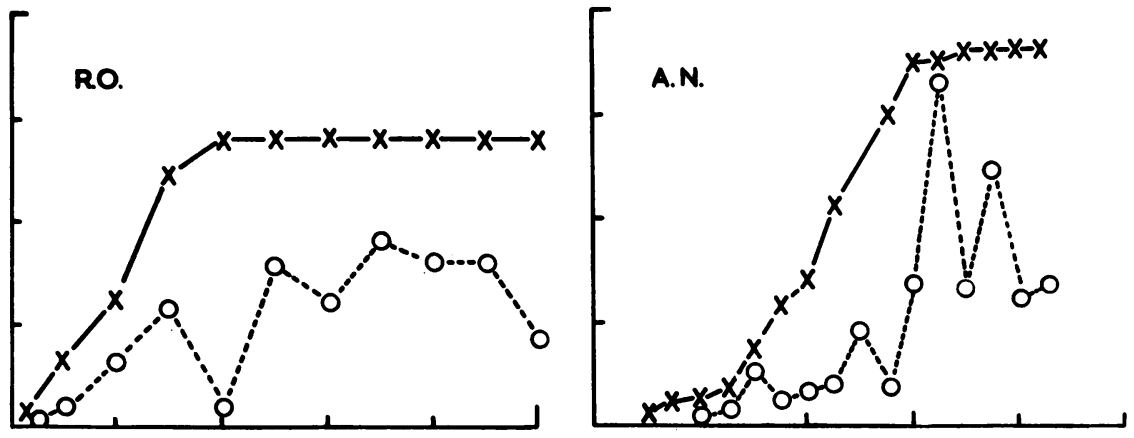

FIG. 1. Relationship between stimulus strength (abscissa) and peak amplitude of direct motor response $(X s)$ and spinal responses (open circles $=$ normal subjects; solid circles $=$ subjects with a lesion of the upper
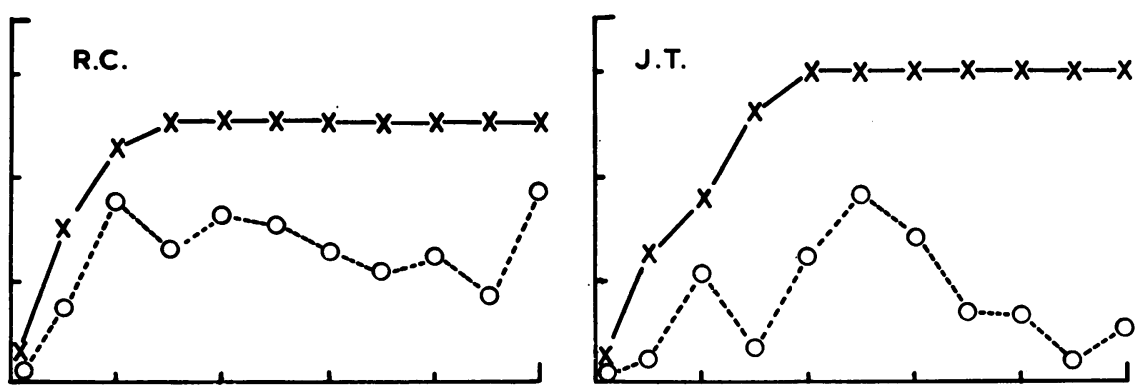
motor neurone involving the muscles under study). Each point represents the mean of 20 readings. Potential recorded from two bare needles inserted $2.5 \mathrm{~cm}$. apart. Ordinate calibrated in arbitrary units.
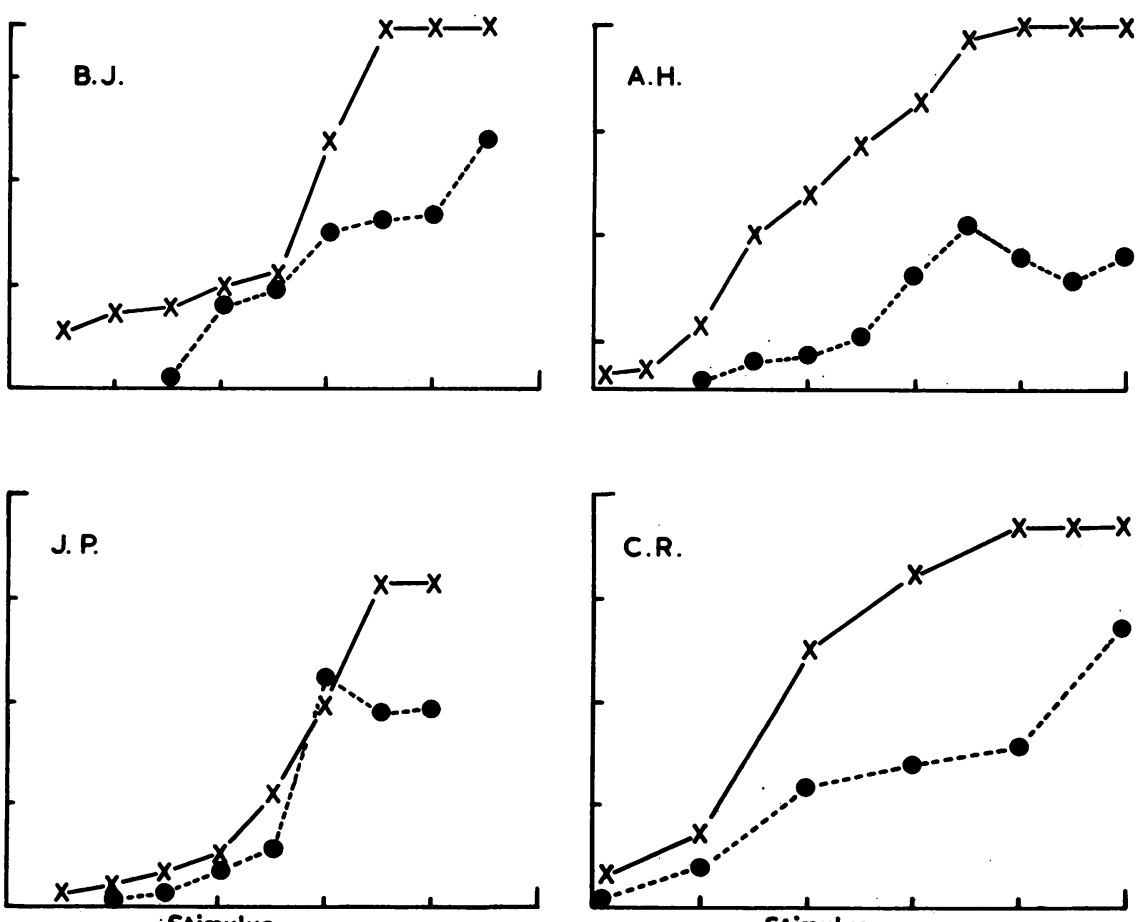

Stimulus

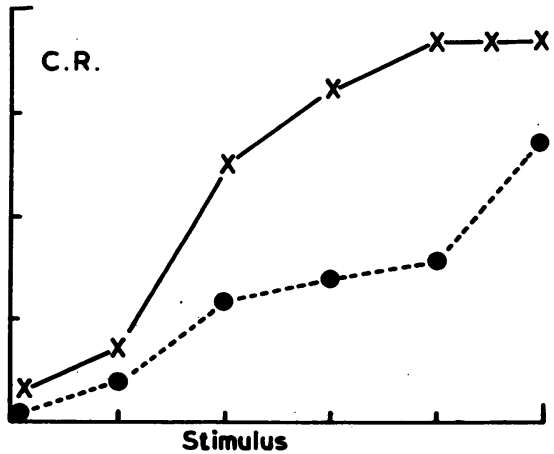


afferent innervation, retained a fair degree of dexterity, that prompted the conjecture by Magladery and McDougal that the $F$ wave might represent activity in a reflex pathway, the afferent limb of which had escaped the pathological process, providing an alternative or additional means of control of skilled movements and posture.

Finally the $F$ response has been found only in the muscles supplied by the nerve being stimulated.

THRESHOLD The appearance of the reflex described by Hoffmann (1918) at stimulus intensities below the threshold of motor fibres was an important observation in determining the nature of the reflex observed. The hypothesis put forward by Hoffmann that this was a monosynaptic reflex using a rapidly conducting afferent pathway was later proven by Lloyd (1943). Characteristically, as the stimulus intensity was increased, the $\mathbf{H}$ reflex amplitude increased in size until the direct motor response appeared once the motor threshold was reached. A further increase in the stimulus resulted in a depression of the reflex response as recorded at the muscle owing to the block of the descending impulses by the ascending antidromic impulses.

When considering the relationship between the $F$ response amplitude and the stimulus intensity, the fluctuating size of the response necessitates the determination of the mean of a number of such responses for a given stimulus strength.

At no time, in the course of examination of over a hundred normal subjects, has the $F$ response appeared at stimulus intensities below that for the motor fibres. Plotting the mean of 20 readings at each stimulus intensity and recording from two needles inserted $2.5 \mathrm{~cm}$. apart gives the results shown in Figure 1. The response occurs at or just above the threshold for the motor fibres. Factors affecting the amplitude of the $F$ wave made an accurate assessment of the growth curve of the spinal response difficult. This irregularity of the growth of the $F$ response contrasts with the relatively smooth increments observed with increasing stimulus intensity of the monosynaptic response. The $F$ wave increased in an irregular fashion to reach a ragged plateau at about the same time as the direct motor response reached its plateau. The threshold of the $F$ response varied in different individuals and in different parts of the same muscle when the recording electrode possessed a sufficiently limited range of pick-up. Thus, it was possible to activate a number of efferent motor fibres without any evidence of a spinal response despite a prolonged period of observation. On the other hand, the appearance of a single motor unit in the direct motor response was sometimes ac- companied by the intermittent appearance of a spina $\bar{R}$ response.

LABILITY With adequate mechanical restriction of the limb under study, and a fixed relationship between the stimulus and nerve, the size and hences the number and identity of the motor neurones participating in the monosynaptic response for an. given stimulus is frequently remarkably constant when recorded over an interval of up to an hour or more. This is not, however, an invariable rule as? first observed by Lloyd in animals (1943) and bye Magladery et al. (1951b) and by Paillard (1955) in man.

Contrasting with this constancy of response of the monosynaptic reflex in man is the marked fluctua of tion of the F response which occurs under controlled conditions. The fluctuation in the number of motor neurones contributing to the $F$ response greatl $\overrightarrow{\omega_{\omega}}$ complicates the assessment of the effect of cons trollable influences, such as activation of muscle receptors by stretch or the effect of a conditioning volley preceding a test volley. The factors contributeo ing to this lability will be dealt with later.

EFFECT OF A PRECEDING CONDITIONING VOLLEY \&్d SIZE OF EVOKED TEST RESPONSE The effect of col? ditioning upon the amplitude of the monosynaphic response obtained in man has been described Magladery et al. (1951b).

When examining the refractory period of the response the non-specific factors, i.e., those facters not accessible to experimental control, exert suc $\vec{F}$ marked influence on the excitability of the motos neurones being tested that any effect of a con ditioning volley must be assessed over and above the random fluctuations occurring in the contro $\underline{B}$ response. This difficulty, coupled with the fact that in addition to the antidromic volley entering the cord음 the dorsal root conveys impulses in the group I and II muscle afferents, makes any interpretation of $\overrightarrow{\vec{B}}$ function at a cellular level virtually impossible Figure 2 shows the results obtained in a number of normal subjects. The conditioning and test volleys. were of equal intensities at about half-maximal foㅡㅡㄹ the alpha motor fibres. Because of fluctuation of control responses, each point plotted represents the mean of 20 readings at a given conditioning-test. interval. Only subject R.L. shows a progressive depression of the test response with decreasing conditioning-test intervals which resembles the., depression obtained with the monosynaptic reflex The remainder of the results show no stable pattern? of response apart from marked depression in some cases at short conditioning-test intervals (Fig. 3) and are presented to demonstrate the difference in 

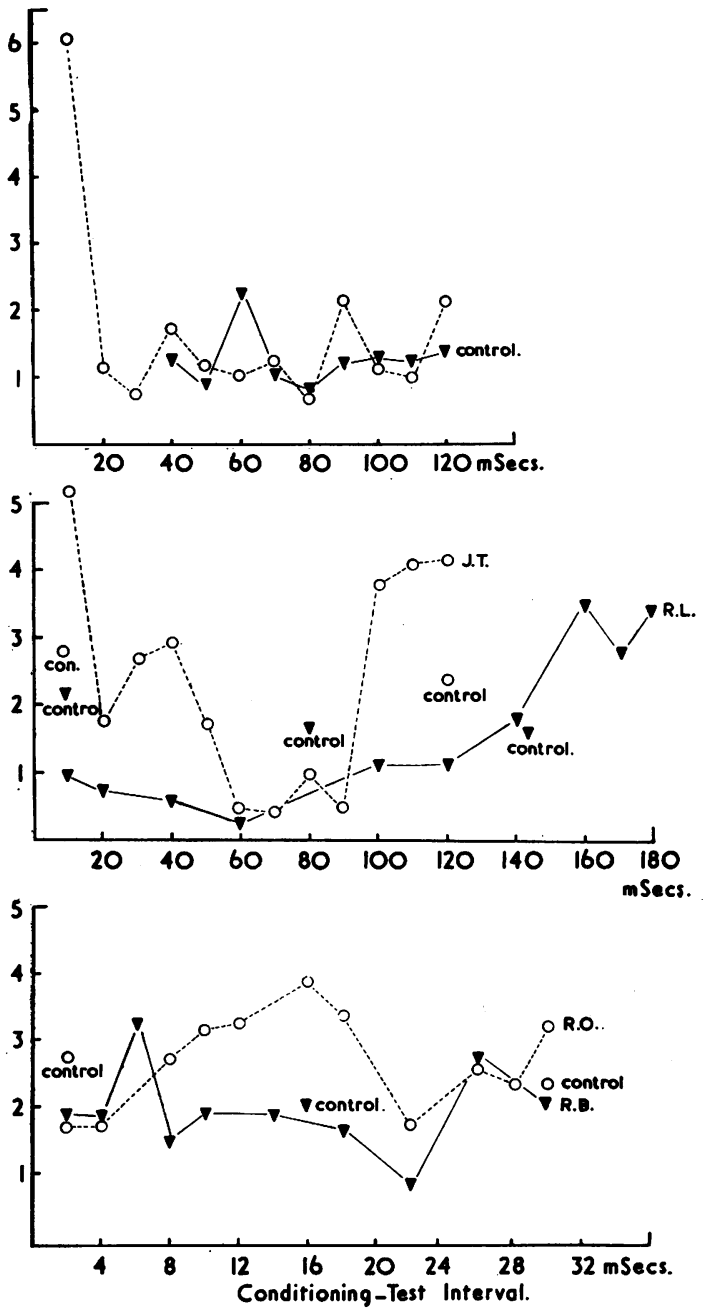

FIG. 2. The effect of a conditioning stimulus on the amplitude of the $F$ response. Conditioning and test stimuli were equal at about half maximal for the motor fibres. Recordings from two bare needles inserted $2.5 \mathrm{~cm}$. apart. Each point represents the mean of 20 readings. Subject in upper graph, and subject J.T. in second graph show some facilitation at 10 msec. Ordinate calibrated in arbitrary units.

response of the $F$ wave to a conditioning stimulus when compared with the monosynaptic reflex. Even with the conditioning-test stimuli confined to the ventral root, in animal experimentation difficulties arise in the interpretation of the findings. As pointed out by Brooks, Downman, and Eccles (1950), two groups of motor neurones are being tested: first those which have been invaded by the antidromic volley and pass through a refractory period, a relatively supernormal period and a phase of sub-

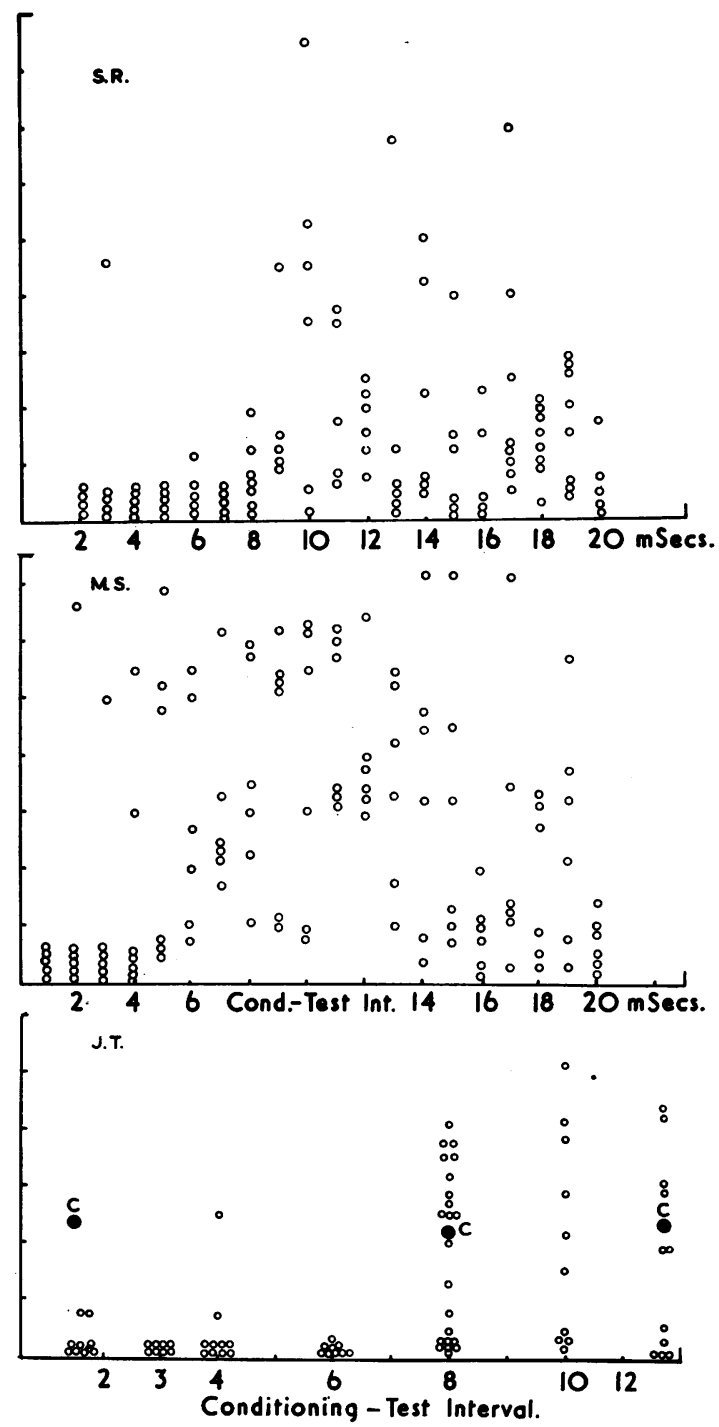

FIG. 3. Recording and stimulating methods as for Figure 2. Each point represents a single observation of peak amplitude of the $F$ response. Note the depression seen at short $C-T$ intervals. Ordinate calibrated in arbitrary units.

normality, and secondly, those in which the antidromic volley fails to invade the soma and dendrites but generates therein merely a subliminal catelectronus with the accompanying increase in excitability.

POST-Tetanic POTENTIATION Post-tetanic potentiation of the monosynaptic pathway has been demonstrated in the monosynaptic reflexes of animals (Lloyd, 1949; Eccles and Rall, 1951). It was found to be limited to the monosynaptic pathway and there 
was no increase in excitability of the motor neurones as tested by an antidromic volley. This suggested that the enhancement of reflex activation was due to a change confined to the presynaptic pathway, as was later confirmed by Wall and Johnson (1958). In man post-tetanic potentiation was demonstrated in the calf muscles of both the monosynaptic reflex elicited from the popliteal fossa and of the ankle tendon reflex by Hagbarth (1962). He demonstrated too that by tetanization the $F$ response could be converted to a reflex with all the characteristics of a monosynaptic reflex.

The absence of post-tetanic potentiation of the $F$ response in normal subjects, experienced in the present study, suggests a mode of production different from the monosynaptic response or even a polysynaptic response since, as pointed out by Dowman, Eccles, and McIntyre (1953), post-tetanic potentiation is not a phenomenon confined to monosynaptic pathways but appears in polysynaptic pathways as well.

Despite marked differences in characteristics between the $F$ response and monosynaptic reflex, it cannot be stated with certainty on the basis of these findings that the response does not arise from monosynaptic activation of the motor neurones as suggested by Hagbarth (1962) and Vylicky (1962) or from polysnaptic pathways as put forward by Magladery et al. (1951a).

An examination of the response, using conventional concentric needle electrodes or bared needles placed several centimetres apart, does not permit the determination of the individual motor units comprising the early direct response and the response arising in the spinal cord. It was felt that such a determination might assist in deciding whether the last response arose from synaptic activation of the motor neurones, i.e., whether it was a true reflex or whether it was produced by the antidromic activation of the motor neurone soma or initial segment.

A narrow range bipolar concentric electrode was therefore employed to provide adequate isolation and identification of the motor units present.

SINGLE UNIT STUDIES OF THE F RESPONSE IN NORMAL SUBJECTS A bipolar concentric needle electrode was constructed using two pieces of 40 S.W.G. enamelled stainless steel wire embedded in araldite inside a $1 \frac{3}{4}$ in. dental needle. Using this electrode, the motor units comprising the $F$ response were isolated and compared with the units represented in the direct motor response. The electrode allows the sharp localization of single motor units identified by their 'all-or-none' behaviour. In order to avoid the low amplitude in-phase components produced by activit居 in distant units, units appearing at threshold were more sharply located by advancing or withdrawing the electrode until a sharp spike was obtained. Having isolated a single unit in the direct response in this way, stimulation was continued until a late responsee appeared, or until it was obvious after a long perios? of stimulation that no response was likely to appearo

In over 30 normal subjects examined in this ways. $F$ responses at latencies varying between 28 and 3 msec. were obtained in all but four of the subjects? In these four, small $F$ responses could be obtained at higher stimulus intensities which, even with the bipolar electrode, produced a very complex direct motor response. In the remainder of the subjects a $F$ response could be obtained at, or just above threshold stimulus for motor nerve fibres.

A number of recordings made up of single or smali groups of motor units is shown in Figure 4.

When the direct motor response was confined to single unit, the late response when it appeared con sisted of that same unit in isolation. There was no deviation from this observation in all normal sub jects examined.

It was not always possible to obtain a spiga保 response while confining the activation to the untit first selected. An alteration of the position of stimulating electrode in relation to the nerve trumb was necessary in order to activate another unitein isolation. While maintaining the stimulating e $R$ trode position constant an increase in the stimu strength was not always successful in producing $a$ spinal response, since the stimulus incremento frequently complicated the direct motor response byer discharging several new units within the range of the electrode.

Figure 5 shows the summation of unit $A$ appearing in trace 1 , with unit $B$ appearing in trace 2 to prod duce the complex of trace 3 . In the fourth trace thळ spinal response consists of unit $\mathrm{B}$ in isolation while the last trace shows at higher amplification units $A \vec{Q}$ and $B$ summated in both early direct and late spina?, responses. There has been a slight shift in the electrode position in the last trace with reduction in the size of the initicl downward deflection.

In Figure 6 the first two traces show two units in isolation in the direct response with, in the following trace, unit $Y$ appearing by itself in the late wave Maintaining units $X$ and $Y$ summated in the direce. response it was not found possible to obtain the two units together in the $F$ response. The inclusion of at third unit, $Z$, however, resulted in the appearance of the two original units summated in the $F$ response? The difference in appearance between the summated responses in the direct traces 3 and 4 and in the spinal response, trace 6 , can be accounted for on the 


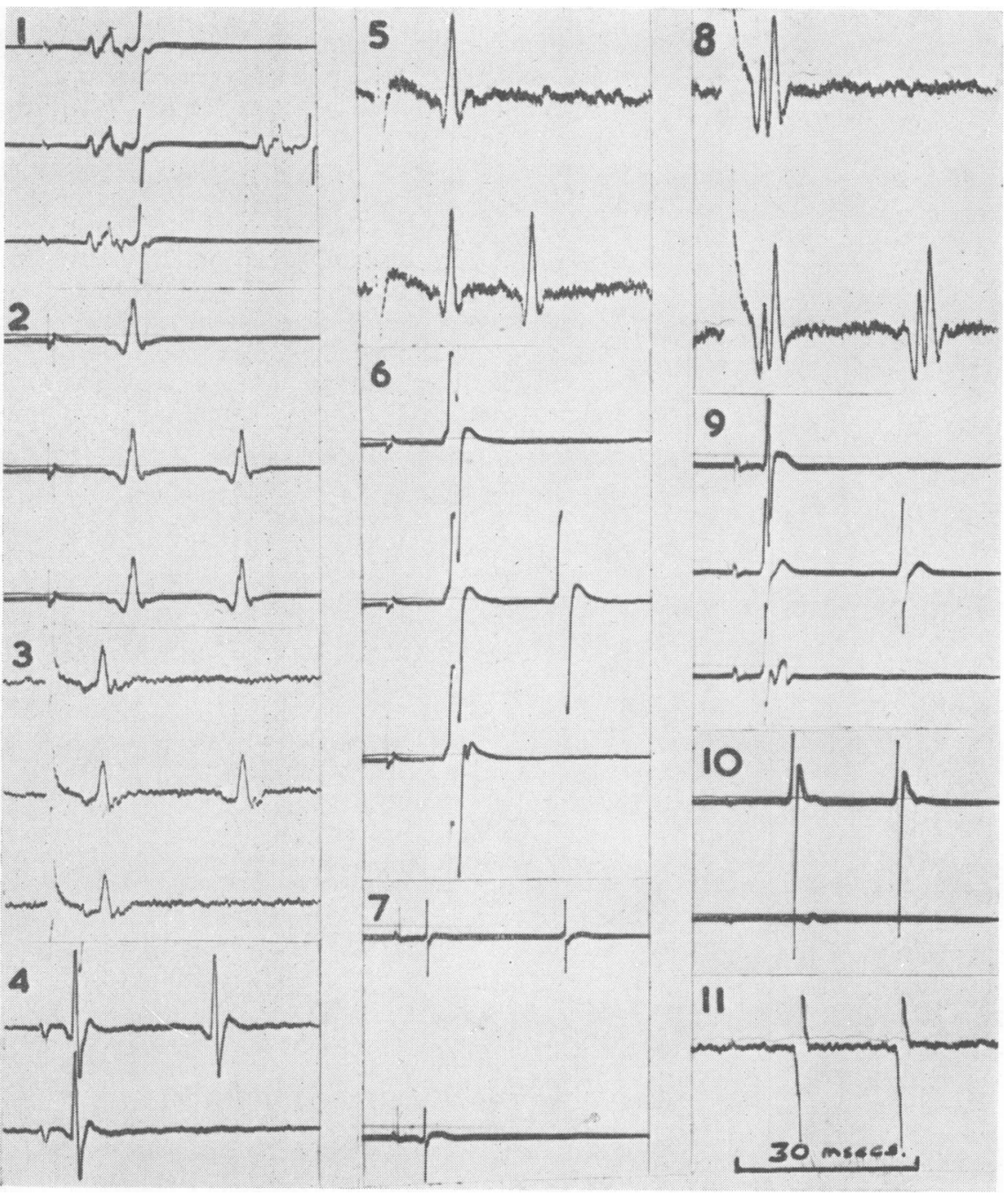

FIG. 4. Recordings from the first dorsal interosseus muscle of 11 normal subjects using a bipolar concentric needle electrode. The stimulus was applied via a bipolar surface electrode to the ulnar nerve at the wrist or elbow. Note that no motor units appear in the late response of central origin that are not represented in the early direct response.

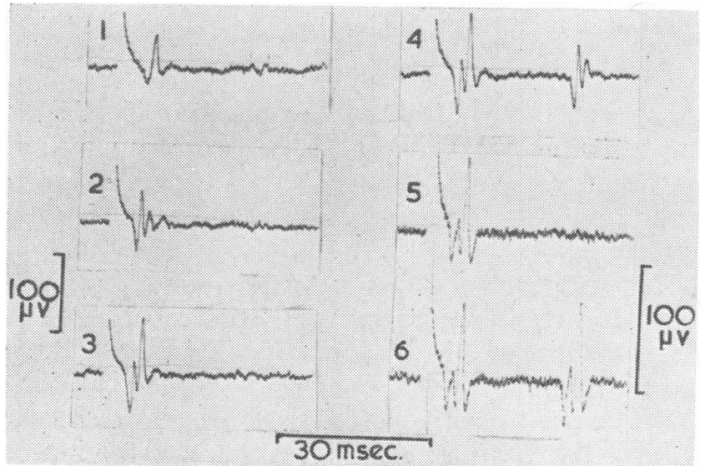

FIG. 5. Recordings from the first dorsal interosseus muscle of a normal subject using a bipolar concentric needle electrode. The stimulus was applied to the ulnar nerve at the wrist. A single motor unit is present in the direct response in trace 1. A slight shift in stimulating electrode position has resulted in another unit appearing in trace 2. With a slight increase in stimulus strength both units have been activated together with their summation in the direct response, trace 3. One of the motor units comprises the late response in trace 4 with both summated in the late response of trace 6, shown at higher amplification. 


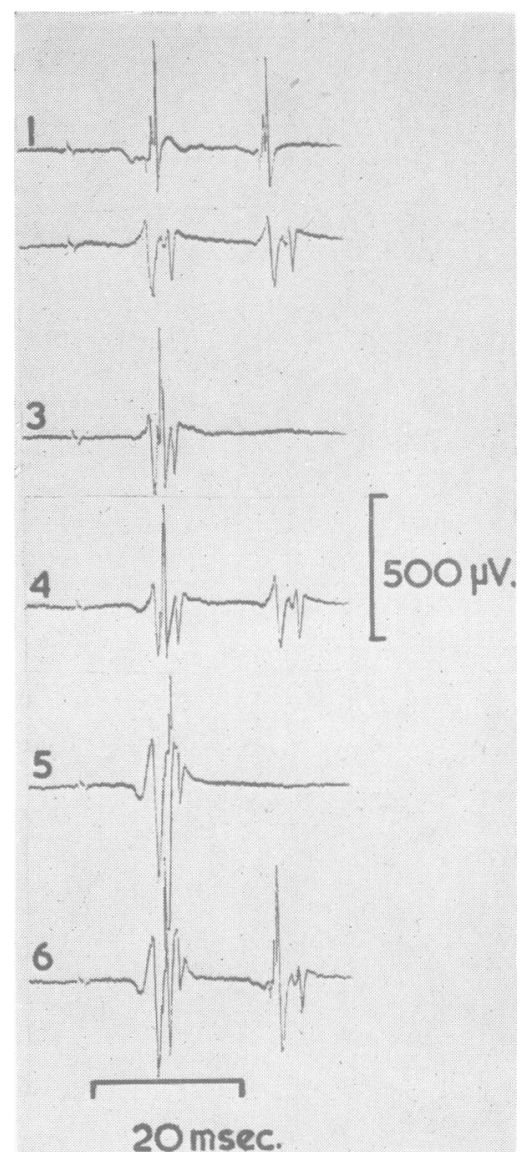

FIG. 6. Recording and stimulating as in Figure 5. The first two traces show two units, units $X$ and $Y$, in both direct and spinal responses. These two units are summated in the direct response of traces 3 and 4, with unit $Y$ in isolation in the late response of trace 4. The addition of a third unit to the direct response achieved by an increase in stimulus strength has resulted in the appearance of units $X$ and $Y$ summated in the late response of central origin seen in trace 6. The slight difference between the configuration of the two units summated in the early and late responses is due to the greater distance travelled by those impulses traversing the cord.

basis of the greater degree of temporal dispersion experienced by the impulses traversing the cord.

Up to three units have been observed simultaneously in the direct and spinal responses with at no time any unit appearing in the late response that was not represented in the direct response.

The different motor units comprising the direct motor response may be represented individually in the $F$ response as shown in successive traces separated by $2 \mathrm{sec}$. in Figure 7. The rather complex potential of the $F$ response in the first trace reproduced later in the direct and late responses, trace 6, would seem to be made up of several motor units. This complex behaved, however, in an all or none fashion for over $\mathbf{4 0}$ or more stimuli despite attempts to separate it into its component parts and appeared as shown in the spinal response on four or five occasions. It was therefore assumed to represent a single unit. The second, third, and fourth traces $\vec{₹}$ contain three new units in the $\mathrm{F}$ response. Manipulation of the stimulating electrode in relation to the nerve trunk permitted the isolation of two of the $\overline{0}$ units in the direct response, each of which has been 흘 coupled with an $\mathrm{F}$ response comprising that unit $\frac{\bar{\rho}}{\frac{}{\sigma}}$ alone.
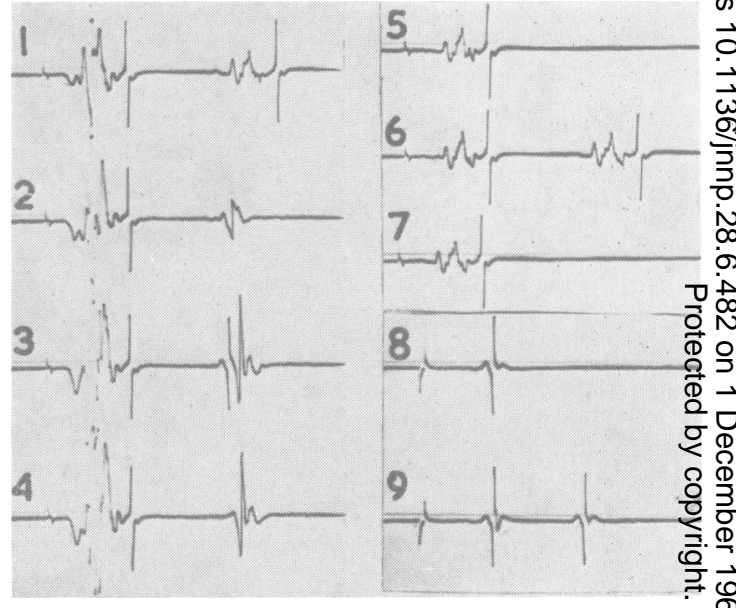

FIG. 7. Traces 1 to 4 show a complete direct motor of response with four different motor units represented in the spinal responses in successive traces (the same unit has appeared in traces 3 and 4 , in trace 3 summated with another unit). Two of the units seen in isolation in the spinal response of traces 1 to 4 have been obtained in isolation in the direct response of traces 5 to 9. In traces 6 and 9 (the latter $\stackrel{\mathbb{Q}}{\Omega}$ elicited from a more proximal point on the nerve) the same $\overrightarrow{\overrightarrow{\vec{A}}}$ motor unit has been obtained in the spinal response as is $\frac{0}{3}$ represented in the direct response.

The constancy of these observations in a large number of normal subjects suggests the conclusions $-{ }^{2}$ that the centrifugal impulses generated centrally occupy only those axons which were antidromically activated.

This property of the $\mathrm{F}$ response constitutes evidence for its identification with the recurrent dis-으.-, charges observed in animals by Renshaw (1941) and Lloyd (1943).

The criterion of reflex activation of a motor neurone has been taken as a response of the motor $\%$ neurone to an ascending volley in the mixed nerve $N$ 
without any evidence of antidromic activity in its axon. This is readily satisfied in the small muscles of the hand and foot in patients with a lesion of the upper motor neurone, but on no occasion has it been found in the muscles of a normal relaxed subject.

SPINAL RESPONSES IN SUBJECTS WITH LESIONS OF THE UPPER MOTOR NEURONE

Electrically induced reflexes in patients with lesions of the upper motor neurone have been studied by a number of investigators. Magladery and McDougal (1950), Magladery et al. (1951a, 1951b), and Magladery, Teasdall, Park, and Languth (1952) observed the reduction in the period of depression of an evoked monosynaptic reflex immediately following a conditioning volley in subjects with spastic lower limbs. In addition the period of depression, which occurs $300-500 \mathrm{msec}$. after the conditioning volley in normal subjects, was diminished in these patients. However, little difference in the threshold of the reflex was observed.

Hohmann and Goodgold (1961) reported that monosynaptic reflexes could be elicited in the anterolateral muscles of the lower limb of some patients with hemiplegia, and the finding of a reflex response in the muscles of the hypothenar group in infants before maturation of the central nervous system (Thomas and Lambert, 1960) led to the further investigation of these muscles in young patients. It was then shown that there were reflex responses to electrical stimulation of the peripheral nerve which complied with the criteria of monosynaptic reflexes in a number of pathological conditions (Hodes and Gribetz, 1962; French, Clark, Butler, and Teasdall, 1961).

The same characteristic features of the Hoffmann response were described by Teasdall, Park, Languth, and Magladery (1952) in peripheral muscles involved by lesions of the lower brain-stem and spinal cord. Vyklický (1962) has also described a reflex obtained in the ulnar-supplied muscles of the hand of a patient with a spastic hemiparesis, which conformed with the criteria of the monosynaptic reflex.

The following account is concerned with some of the features of the electrically evoked reflexes found in the small muscles of the hand in patients with lesions of the upper motor neurone.

TRUE REFLEX RESPONSE In a series of 15 patients with lesions of the upper motor neurone involving the small muscles of the hand, a pattern of reflex response has been observed which differs in fundamental respects from the $F$ response obtained from healthy subjects. This alteration in behaviour has been found in about two-thirds of the number examined. In the remainder, the late response was depressed to the point of complete absence in two subjects, with the retention of the normally evoked $F$ response in the three others.

The main feature of this change has been the emergence of a true reflex response. In three cases in which the response has been evoked at a threshold, below that for the motor fibres, the reflex nature has been immediately apparent. In some cases, however, using conventional concentric needle electrodes the spinal response on first examination has been indistinguishable from normal $F$ waves. The responses appeared at stimulus intensities sufficiently high to evoke a response in the alpha efferent fibres. They exhibited a fluctuation in size and failed to be attenuated by the antidromic activation of motor fibres, in response to maximal or near maximal stimuli-all characteristics of the $F$ response. They are distinguishable from the $F$ response by identifying different motor units in the spinal and direct response using the bipolar concentric needle electrode.

LOW THRESHOLD REFLEX RESPONSES In a variety of disorders involving the central nervous system Teasdall et al. (1952), Hodes and Gribetz (1962), French et al. (1961), and Vyklický (1962) have described a low threshold response of long latency. The spinal responses described in each case have been found at stimulus intensities below that for the alpha motor fibres and have been identified as monosynaptic reflexes by these investigators.

Shown in Fig. 8 in the upper of the paired traces, is a low threshold reflex evoked from the first dorsal interosseus muscle, the stimulus being applied to the ulnar nerve at the wrist. An increase in stimulus produced a direct motor response and an increase in the size of the reflex. The three paired traces $(5,6$, and 7$)$, shown on the right of Fig. 8 were obtained with a constant stimulus intensity. The constant early triphasic component at $30 \mathrm{msec}$. in the upper trace is followed by a variable component reflexly produced since its constituent motor units are not present in the direct response. This later reflex component only appeared at the same threshold as that of fibres in the alpha motor spectrum and will be discussed later. In a small number of subjects with spasticity of the limb under study a reflex has been recorded from the flexor carpi ulnaris muscle in addition to the reflex appearing in the intrinsic hand muscles in response to stimulation of the ulnar nerve at the wrist. The potentials recorded from the flexor carpi ulnaris using a concentric needle electrode arc shown in Figure 9. The upper trace of the pairs shown demonstrates the potentials from the first dorsal 


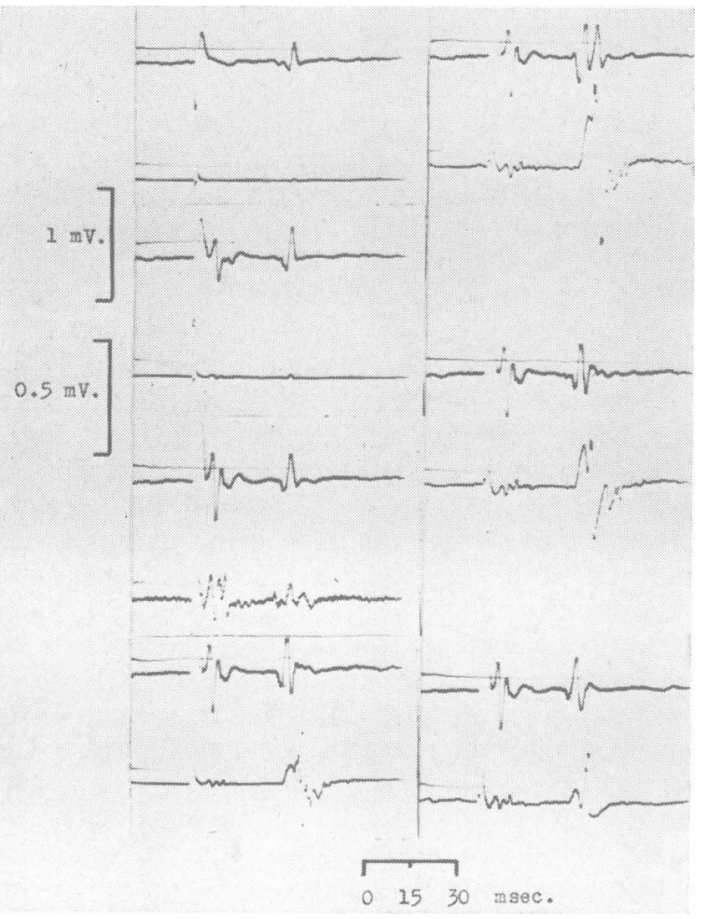

FIG. 8. Recordings from first dorsal interosseus muscle of a subjest with a spastic quadriparesis. Upper trace of paired traces obtained from a conventional concentric needle elestrode the lower trace from a bipolar concentric needle electrode. The large initial deflection in the first and subsequent traces is the stimulus artifact. The left hand column of traces obtained at increasing stimulus strengths shows a low threshold spinal response appearing below the threshold for the motor fibres (upper trace). In the right hand column of traces, obtained at a constant stimulus intensity, the records obtained from the conventional concentric needle electrode show two components to the late response. An early moderately constant triphasic potential followed by a variable polyphasic component. The reflex nature of this late component is confirmed in the trace from the bipolar needle (lower trace) which shows the small direct response followed by the large variable reflex comprised of units not contained in the direct response.

interosseus, an early direct or $M$ response and the late spinal response. In the lower record the response is shown from the flexor carpi ulnaris occurring at a latency of $23 \mathrm{msec}$. The second and third traces and the fourth and fifth traces are at equal stimulus strengths. The response from the long flexor muscle has a moderately regular basic configuration, traces 2 and 3 being identical in shape. It is clear, however, that a difference in units constituting the reflex exists between traces 4 and 5 .

The late response of the first dorsal interoeseus muscle, although differing in records obtained at the same stimulus intensity, all possessed a small con- $\bar{Z}$ stant early component and a general shape more regular than the $F$ wave found in normal subjects. This reduced variability of the spinal response has

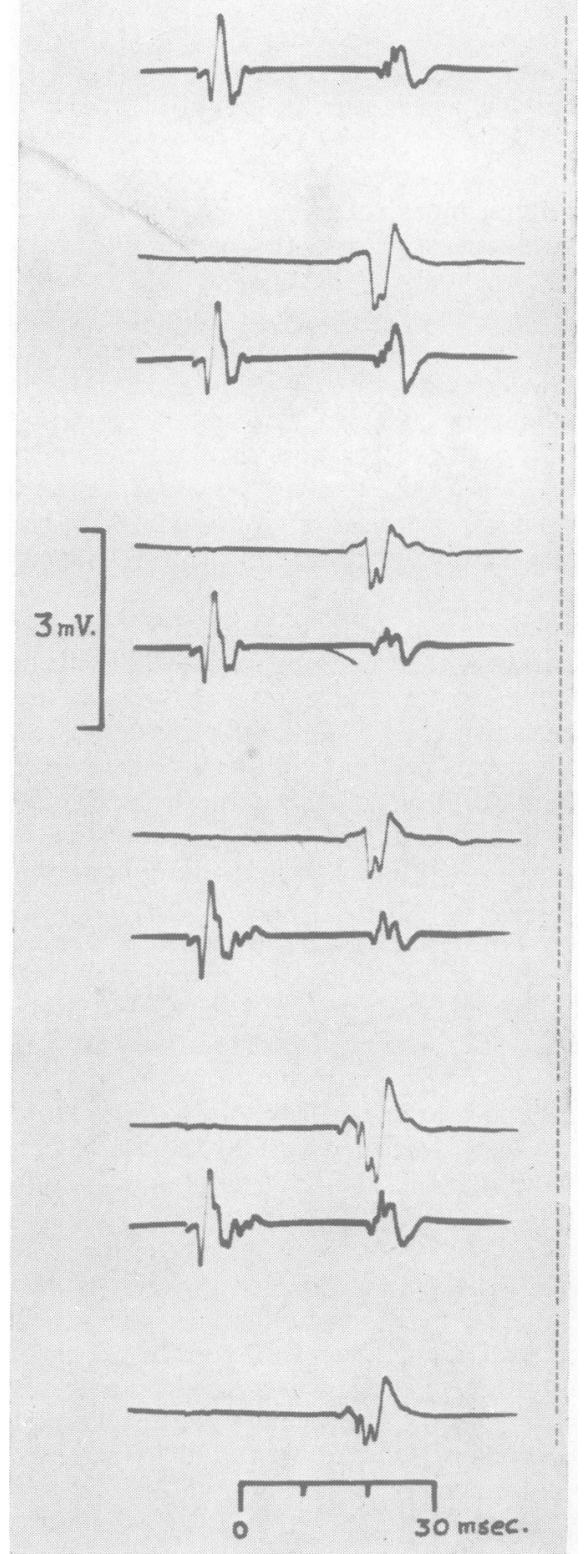

FIG. 9. Potentials recorded from a concentric needle electrode inserted in the first dorsal interosseus muscle (upper trace) and the flexor carpi ulnaris muscle (lower trace), in response to stimulation of the ulnar nerve at the wrist. The reflex appears in the flexor carpi ulnaris $23 \mathrm{msec}$. after the application of the stimulus. 
been observed as a feature of spastic limbs, where in addition to the labile antidromic component, a more constant true reflex component increased the mean value of the central responses on the spastic side, although significant lowering of threshold was not a prominent feature.

The relative thresholds and growth curves of the direct motor response, the late deflection from the first dorsal interosseus and flexor carpi ulnaris are shown in Figure 10. It appears from this graph that the afferent fibres mediating the reflex from flexor carpi ulnaris as well as those fibres involved on the afferent side of the reflex component obtained from the first dorsal interosseus have a higher threshold than the direct motor response and probably lie within the group II afferent nerve fibre spectrum.

HIGH THRESHOLD REFLEX RESPONSES Further support for the incrimination of the group II fibres in the production of abnormal reflex behaviour in the small muscles arises from a closer examination of the late deflections obtained in these muscles in patients with an upper motor neurone lesion.

The demonstration of the high threshold reflex component of the electrically evoked response in subj zcts with lesions of the upper motor neurone is complicated when using conventional concentric needle electrodes by the complexity of the direct motor response obtained at the stimulus intensities necessary. The approximation of the narrow range bipolar concentric needle to the motor unit or units represented in the late response allows the

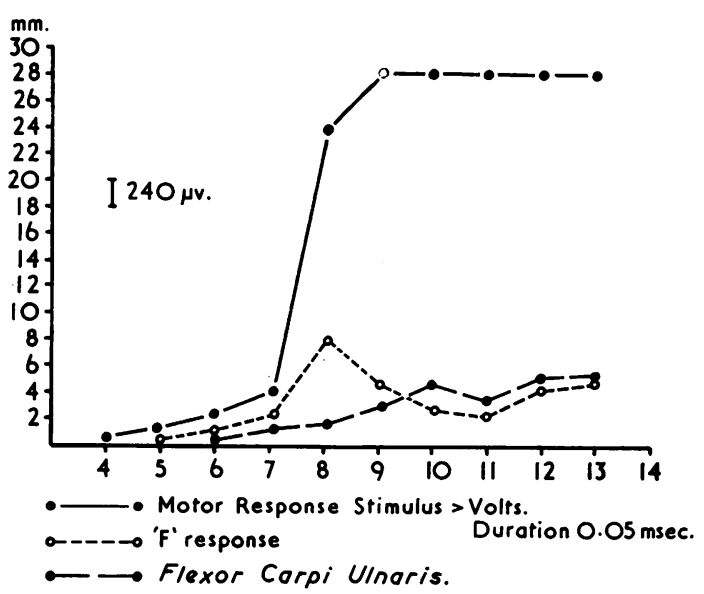

FIG. 10. Growth curves of direct motor response (closed circles and lines), late response (open circles and interrupted line) from the first dorsal interosseus muscle, and the late response from the flexor carpi ulnaris (closed circles and interrupted lines). Concentric needle electrode used. Each point represents the mean of 10 readings. separation of units reflexly activated from those antidromically activated.

The bipolar concentric needle was advanced to a position close to the units reflexly activated, providing attenuation of the potentials from the rest of the muscle fibres directly activated. The increase in relative amplitudes of the spinal and direct motor response enabled the positive identification of motor units reflexly activated, separating them from those units contained in the direct response.

Figure 11 obtained from another patient with spasticity shows the true reflex nature of a component of the late deflection. The spinal response recorded in traces 1 and 3 could on first examination have been an antidromic response. Accurate location of the units represented, using a bipolar concentric needle electrode, confirms, however, that the units in the late deflection were synaptically activated. Similarly in Fig. 12, recorded from a bipolar concentric needle electrode, traces 2 and 4 contain units in the late response not represented in the orthodromic motor response. Apart from the constant triphasic component present at lower stimulus intensities in the upper of the paired traces of Fig. 8, the later components of this response occurred at higher stimulus intensities and could not positively be identified as being reflex in nature (traces 5-7). The lower trace of the paired traces was recorded using the narrow range electrode, confirming the reflex nature of part of the late response.

The summation of an orthodromically activated

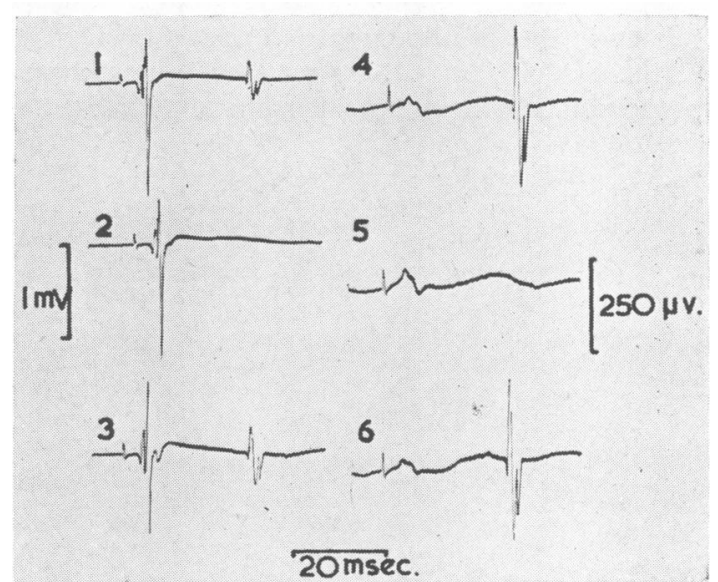

FIG. 11. Recordings from the first dorsal interosseus muscle of a patient with an intracerebral lesion causing upper motor neurone symptoms in the limb under investigation. Intermittent spinal responses seen here in traces 4 and 6 have been identified as arising from orthodromic activation of the motor neurone. Bipolar concentric needle electrode used. 


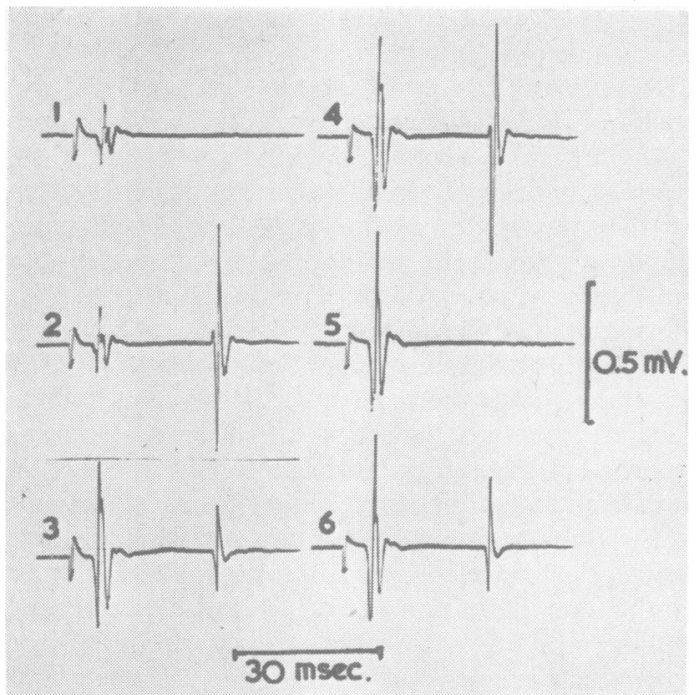

FIG. 12. Recordings from the first dorsal interosseus muscle of a subject with an upper motor neurone lesion. Spinal responses in traces 2 and 4 are not represented in the direct response but have been orthodromically activated. Bipolar concentric needle electrode used.

motor unit with one antidromically activated is shown in Figure 13. The single unit appearing in the late response in trace 1 is represented in the direct motor response (summated in traces $1-10$ with at least one other motor unit). This unit represents the normal antidromic $F$ response. The same unit appears isolated in the direct response in trace 12.

Traces 6,10 , and 11 show a reflexly activated motor unit which in trace 8 has summated in the spinal response with the deflection arising from the $\bar{Z}$ antidromically activated unit.

Additional evidence for the emergence of a true reflex pathway between afferent fibres not normally capable of inducing firing in the motor neurones with which they synapse has been obtained in subjects with lesions of the upper motor neurone. This took the form of post-tetanic potentiation of the spinal response. As stated by Eccles (1953), potentiation of reflex responses following tetanization of the peripheral nerve is not evident when the excita- $\stackrel{?}{\rightarrow}$ bility of the motor neurone pool is measured by antidromic volleys.

Antidromic invasion and recurrent impulse $\frac{\overline{\bar{\omega}}}{\bar{a}}$ formation cannot be expected to be enhanced by this $\stackrel{\mathbb{}}{\square}$ technique, unless the tetanization by means of the potentiation of the monosynaptic or polysynaptic pathway increased the 'background' synaptic activity which is known to facilitate antidromic invasion. $\vec{\omega}$ This has not been found to be the case with sub-S motor threshold tetanizing stimuli in normal subjects. Figure 14 shows the effect of a 90-second submotor-threshold tetanus at 50 stimuli per second $\infty$ applied to the ulnar nerve at the wrist, the reflex response being recorded from the first dorsal intes osseus muscle. The period of facilitation lasted $\mathrm{m}_{0}$ this case for about six seconds following the tetanus. The range of variation of the amplitude of the spinal responses obtained before tetanization is narrower than that obtained for the $F$ response in normgl subjects. Reference to Fig. 1, where the summated muscle responses to both direct activation and activation arising centrally have been plotted against $\overrightarrow{0}$ stimulus strength in a number of spastic limbs, of indicates a reflex threshold close to, or higher than, that of the alpha motor fibres. Although this has

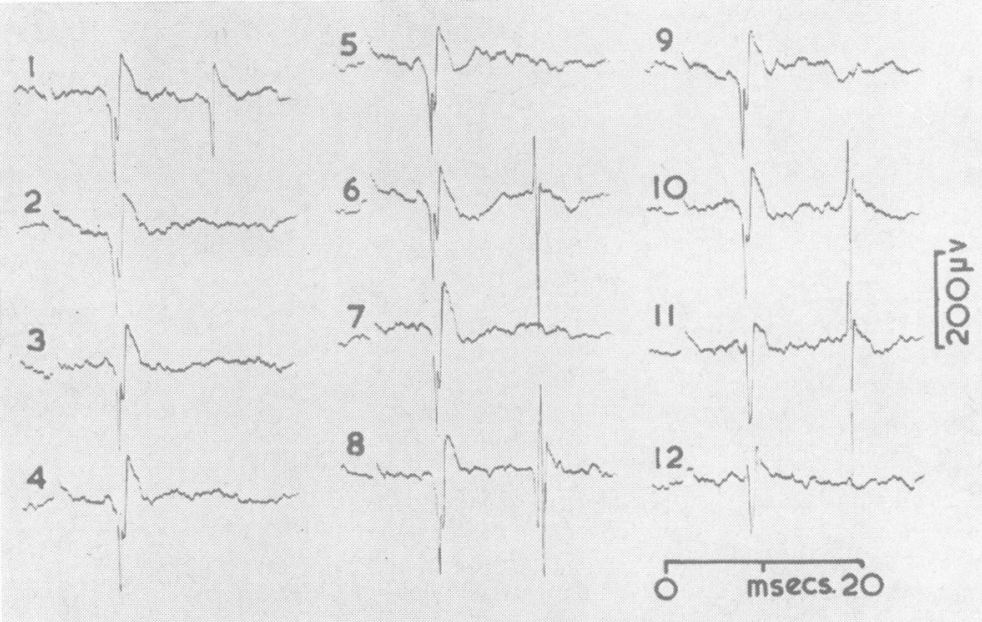

FIG. 13. Records from the first $\frac{\overline{\mathrm{O}}}{3}$ dorsal interosseus muscle of $a$ subject with an upper motor neurone lesion involving the hand. The antidromically activated motor unit seen in trace 1 has summated with the reflexly activated units seen in traces 6,10 , and 11 , to give the late deflection shown in trace ? 8. Stimulus applied to the ulnar 3 nerve at the wrist. 


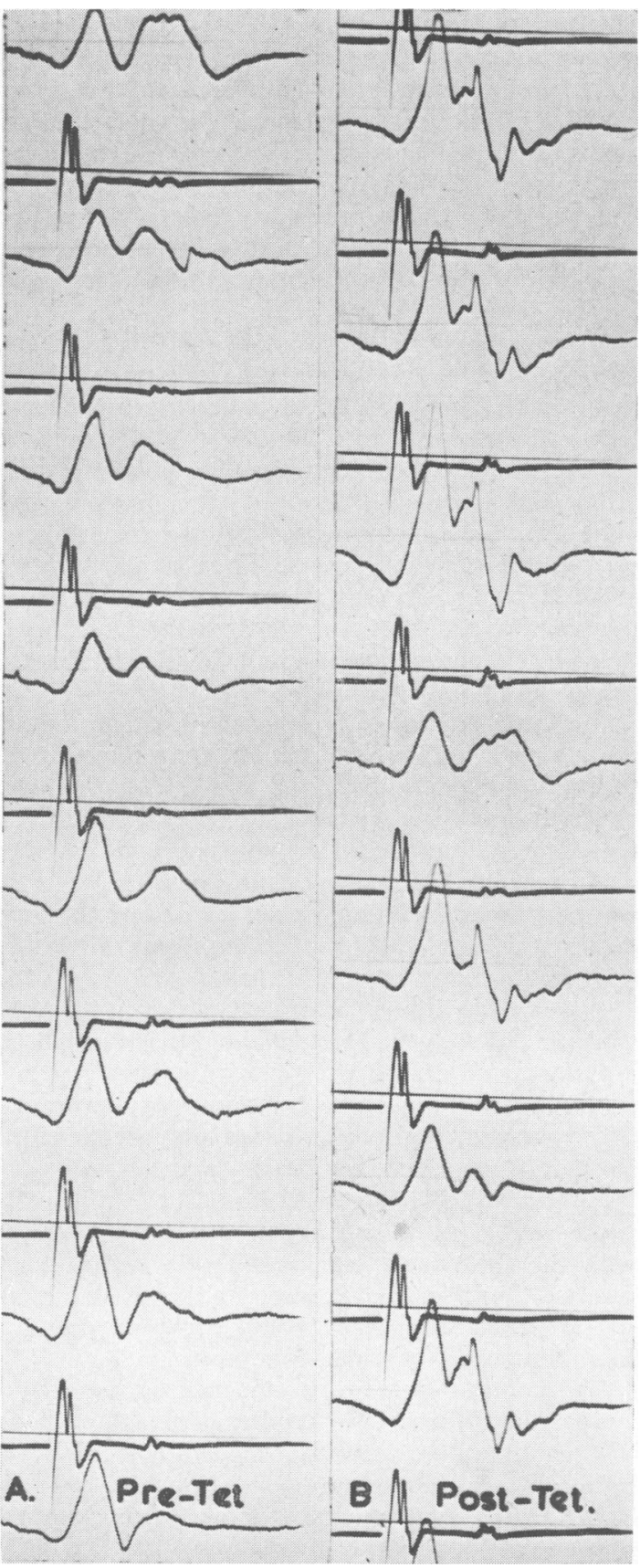

FIG. 14. Post-tetanic potentiation of the spinal response obtained from the first dorsal interosseus muscle of a subject with an upper motor neurone lesion. The late deflection has been expanded, and amplified in the upper trace. Potentiation of both the early triphasic component and of the later polyphasic component has occurred. Stimulus was applied to the ulnar nerve at the wrist. been a consistent finding it was thought advisable to examine the reflex threshold relative to the nerve action potential, the peak height of which represents conduction in the rapidly conducting low threshold afferent fibres (Dawson, 1956). Figure 15 shows the results obtained when the amplitude of the nerve action potential from the ulnar nerve at the elbow, the direct muscle response, and the reflex response have been plotted against an increasing stimulus intensity. Each point represents the mean of 10 readings. It is apparent from this that the high threshold of the spinal response was not an artifact related to the anatomical peculiarities of the mixed peripheral nerve but that the response appeared only after motor threshold had been reached and at a time when afferent activity in the nerve, as judged by the nerve action potential, had already reached a considerable level.

\section{DISCUSSION}

The single unit studies of the $\mathrm{F}$ response strongly suggest that whatever additional excitatory factors are present, the triggering stimulus of the motor neurones producing the $F$ response arises from the antidromic impulse traversing the alpha motor fibre. Since under constant conditions of stimulation the number and identity of the motor axons antidromically activated is constant, a central factor or factors are responsible for the intermittent appearance of the response. Of the possible factors capable of influencing transmission across the axon-soma junction (Barakan, Downman, and Eccles, 1949), synaptic excitation or inhibition is almost certainly responsible for the lability which is observed.

The spinal response described in the subjects with an upper motor neurone lesion have certain features in common: a component with a threshold which is above that of the fastest alpha efferents; intermittent appearance of part or all of the complex under constant conditions of stimulation; failure to be attenuated by high stimulus intensities.

The first and last factors indicate an afferent pathway made up of fibres slower in conduction velocity than the group 1a spindle afferents.

The intermittent appearance under constant stimulus conditions of the reflex response suggests that either an inter-neurone lies in the reflex pathway, or if the afferent fibres do make monosynaptic connexions with the motor neurone, then the excitatory influence is sufficient to provoke a discharge only if summated with an excitatory post-synaptic potential from another source, possibly the same variable excitatory post-synaptic potential that is intermittently present to facilitate the antidromic invasion of the motor neurone to produce the 

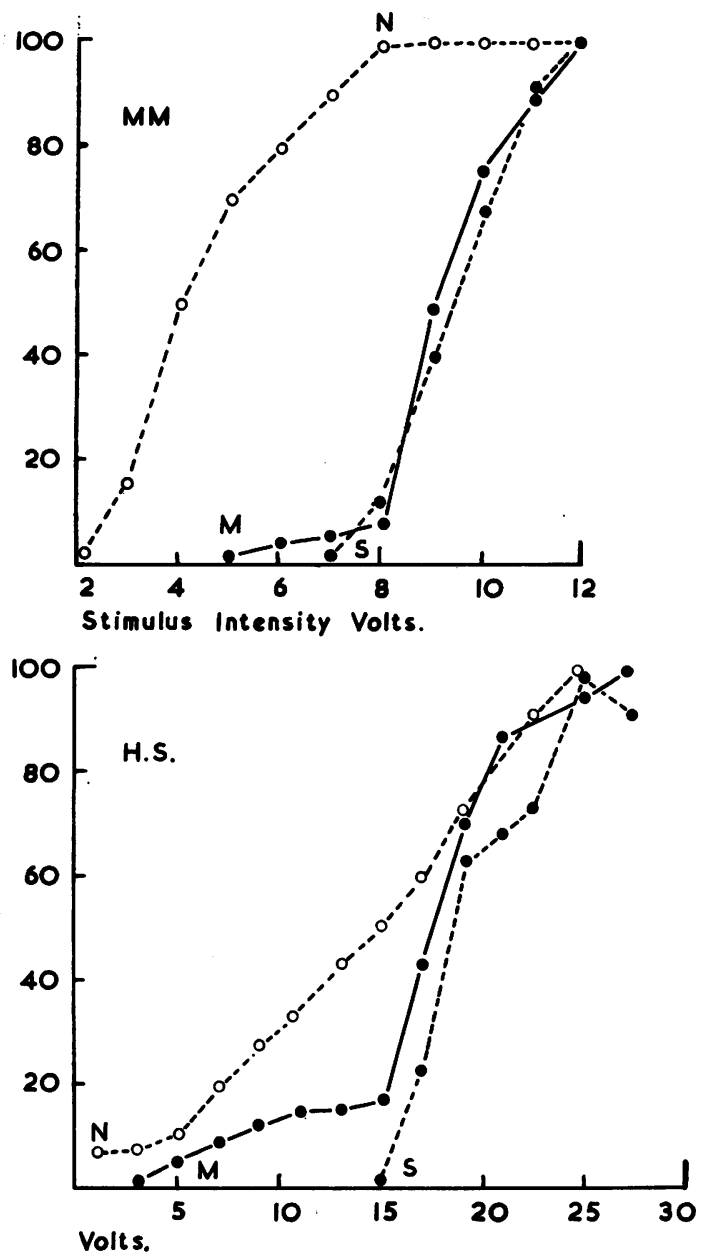

FIG. 15. Growth curves of the nerve action potential recorded from two bare needles at the elbow (open circles, solid line) and peak spinal response (solid circles, interrupted line). Each point mean of 10 readings. Note high threshold of reflex response relative to the nerve action potential. Ordinate expressed as percentage of maximum response.

F response. If the latter explanation is the correct one, one is forced to postulate the presence of high threshold afferent fibres having monosynaptic connexions with anterior horn cells.

Experimental evidence has been obtained (Thorne, 1965) which shows that an accurate interpretation of fibre threshold is not possible when this is assessed from the response to percutaneous stimulation. In view of this, some caution has to be exercised in interpreting the reflex threshold relative to the direct motor response.

As indicated earlier, the monosynaptic reflex obtained in the calf muscles is known to be mediated $\bar{Z}$

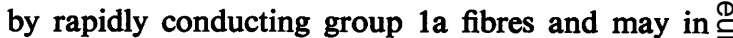
some circumstances (mainly related to the nerve- 0 stimulating electrode relationship) be obtained only at stimulus intensities above that for the alpha fibres. Attenuation of the response with increments in the stimulus intensity demonstrates that although the $\frac{\rho}{?}$ afferent fibres appear to have a higher threshold they do in fact conduct more rapidly than the efferent fibres.

It seems likely on the basis of the threshold and $\stackrel{?}{+}$ variability of the response obtained in the hand muscles of subjects with an upper motor neurone $\frac{\bar{\sigma}}{\bar{N}}$ lesion that it represents activity in a polysynaptic $\frac{\bar{\sigma}}{\vec{\sigma}}$ pathway mediated by the group II muscle afferents. $\triangle$

The reflex response obtained from the proximal $\%$ muscles in response to activation of the peripheral $\vec{D}$ part of the nerve in spastic limbs similarly has a component that arises at stimulus intensities above $\vec{\omega}$

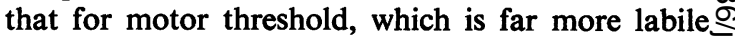
than the monosynaptic response obtained from the $\bar{z}$ larger muscles.

It is concluded therefore that in proximal muscles $\stackrel{\sim}{\infty}$ too reflex irradiation is mediated to some extent ${ }^{\circ}$ by afferent fibres other than group 1 .

The significance of these findings whom integrity of the upper motor neurone has bee disturbed) lies in the demonstration of reflex path ways anatomically intact which in the normal nersous system are subjected to constant inhibitoz influences.

The inter-position of an inter-neurone in the polsynaptic pathway facilitates this plasticity, providir $\overrightarrow{0}$ a pathway of variable transmission dependent upon of supranuclear influences. Supranuclear depression ${ }_{-}$ of a monosynaptic pathway can only occur either at the post-synaptic membrane or at a presynaptic level (Frank and Fuortes, 1957). The facility with which the neurone can be antidromically invaded $\frac{\mathcal{D}}{2}$ with the subsequent production of a centrifugally $\cong$ directed impulse, the $F$ response, tends to favour the latter as being the probable site of constant inhibition under normal conditions.

The constant inhibitory influence on the monosynaptic pathway in the hand muscles is in contradistinction to the muscles of posture from which? an electrically induced monosynaptic response can $\frac{5}{3}$ in most subjects readily be obtained. This raises the question of the extent of the influence that the group la afferents have on the anterior horn cells in the intrinsic hand muscles and whether this influence is 윽 constantly present or only under certain conditions $>$ relating to whether the muscle is 'alpha' or 'gamma'을. driven. It is possible that under dynamic conditions $N$ activation of the anterior horn cells is accompanied by a disinhibition of the monosynaptic arc, allowing 0 
the servo mechanisms mediated by low threshold muscle afferents to come into play. The relative contributions of supranuclear influences and muscle afferents to motor neurone excitability has been examined and is the subject of further study.

\section{SUMMARY}

The $\mathrm{F}$ response has been established to arise from antidromic activation of a small percentage of motor neurones whose axons conduct the antidromic impulses.

This response of spinal cord origin differs in respect of its distribution, threshold, response to conditioning, and lability from the monosynaptic reflex obtained from the large muscles of posture.

Where integrity of the long tracts has been disturbed, a true reflex component is superimposed. This is mediated by both low and high threshold muscle afferents and is found to irradiate proximally.

I would like to express my thanks to Dr. W. Ritchie Russell, Director of the Department of Neurology, United Oxford Hospitals, for his generous support and encouragement. My thanks also go to Dr. G. Rushworth, consultant clinical neurophysiologist, United Oxford Hospitals, for valuable discussion and helpful criticism. I am grateful to the consultants in neurology of the United Oxford Hospitals who permitted free access to the patients in their care.

This work was performed while in receipt of a grant from the Polio Research Fund.

\section{REFERENCES}

Barakan, T. H., Downman, C. B. B., and Eccles, J. C. (1949). Electric potentials generated by antidromic volleys in quadriceps and hamstring motoneurones. J. Neurophysiol., 12, 393-424.

Brooks, C. McC., Downman, C. B. B., and Eccles, J. C. (1950). After-potentials and excitability of spinal motoneurones following antidromic activation. Ibid., 13, 9-38.

Dawson, G. D. (1956). The relative excitability and conduction velocity of sensory and motor nerve fibres in man. J. Physiol., (Lond.), 131, 436-451.

-, and Merton, P. A. (1956). 'Recurrent' discharges from motoneurones. $X X$ Congrès International Physiol. Brussels: Résumés des Communications, p. 221.

Downman, C. B. B., Eccles, J. C., and McIntyre, A. K. (1953), Functional changes in chromatolysed motoneurones. $J$. comp. Neurol., 98, 9-36.

Eccles, J. C. (1953). The Neurophysiological Basis of Mind. Clarendon Press, Oxford.

- , and Rall, W. (1951). Effects induced in a monosynaptic reflexpath by its activation. J. Neurophysiol., 14, 353-376.

Frank, K., and Fuortes, M. G. F. (1957). Presynaptic and postsynaptic inhibition of monosynaptic reflexes. Fed. Proc., 16, $39-40$.
French, J. H., Clark, D. B., Butler, H. G., and Teasdall, R. D. (1961). Phenylketonuria: Some osbervations on reflex activity. J. Pediat., 58, 17-22.

Hagbarth, K. E. (1962). Post-tetanic potentiation of myotatic reflexes in man. J. Neurol. Neurosurg. Psychiat., 25, 1-10.

Hodes, R., and Gribetz, I. (1962). H-reflexes in normal human infants. Depression of these electrically induced reflexes (EIR'S) in sleep. Proc. Soc. exp. Biol. (N.Y.), 110, 577-580.

Hoffmann, P. (1918). Uber die Beziehungen der Sehnenreflexe zur willkürlichen Bewegung und zum Tonus. Z. Biol., 68, 351-370.

Hohmann, T. C., and Goodgold, J. (1961). A study of abnormal reflex patterns in spasticity. A new application of electrodiagnosis. Amer. J. phys. Med., 40, 52.

Liberson, W. T., Zalis, A., Gratzer, M., and Grabinski, A. (1963). Abstract, International E.M.G. Meeting, Copenhagen 1963, p. 138.

Lloyd, D. P. C. (1943). Conduction and synaptic transmission of the reflex response to stretch in spinal cats. J. Neurophysiol., 6, 317-326.

(1949). Post-tetanic potentiation of response in monosynaptic reflex pathways of the spinal cord. J. gen. Physiol., 33, 147-170.

Magladery, J. W., and McDougal, D. B. (1950). Electrophysiological studies of nerve and reflex activity in normal man. I. Identification of certain reflexes in the electromyogram and the conduction velocity of peripheral nerve fibres. Bull. Johns Hopk. Hosp., 86, 265-290.

—, Porter, W. E., Park, A. M., and Teasdall, R. D. (1951a). Electrophysiological studies of nerve and reflex activity in normal man. IV. The two-neurone reflex and identification of certain action potentials from spinal roots and cord. Ibid., 88, 499-519.

_, Teasdall, R. D., Park, A. M., and Porter, W. E. (1951b). Electrophysiological studies of nerve and reflex activity in normal man. V. Excitation and inhibition of two-neurone reflexes by afferent impulses in the same nerve trunk. Ibid., 88, 520-537.

,,-- , and Languth, H. W. (1952). Electrophysiological studies of reflex activity in patients with lesions of the nervous system. I. A comparison of spinal motorneurone excitability following afferent nerve volleys in normal persons and patients with upper motorneurone, lesions. Ibid., 91, 219-244.

Paillard, J. (1955). Analyse électrophysiologique et comparaison, chez l'homme, du réflexe de Hoffmann et du réflexe myotatique. Pflügers Arch. ges. Physiol., 260, 448-479.

(1959). Functional organization of afferent innervation of muscle studied in man by monosynaptic testing. Amer. J. phys. Med., 38, 239-247.

Renshaw, B. (1941). Influence of discharge of motorneurons upon excitation of neighbouring motoneurons. J. Neurophysiol., 4, 167-183.

Teasdall, R. D., Park, A. M., Languth, H. W., and Magladery, J. W. (1952). Electrophysiological studies of reflex activity in patients with lesions of the nervous system. II. Disclosure of normally suppressed monosynaptic reflex discharge of spinal motoneurones by lesions of the lower brain-stem and spinal cord. Bull. Johns Hopk. Hosp., 91, 245-256.

Thomas, J. E., and Lambert, E. H. (1960). Ulnar nerve conduction velocity and H-reflex in infants and children. J. appl. Physiol., 15, $1-9$.

Thorne, J. (1965). An electrophysiological study of spinal reflexes in man. Ph.D. Thesis, Oxford University.

Vyklický, L. (1962). Elektromyograficke projevy Stimulace nervus ulnaris Cloveka. Plzensky lek. Sborn., suppl. 6, 35, pp. 35-75.

Wall, P. D., and Johnson, A. R. (1958). Changes associated with posttetanic potentiation of a monosynaptic reflex. J. Neurophysiol., 21, 148 .

Wiesendanger, M., and Gassell, M. M. (1963). In Abstract, International E.M.G. Meeting, Copenhagen, 1963, p. 178. 